UDK: 629.3.015

DOI: https://doi.org/10.24867/12AM02Jankovic

\title{
DINAMIKA VOZILA U ANALIZI SAOBRAĆAJNIH NEZGODA: MODELIRANJE PRILAZNE FAZE
}

\section{VEHICLE DYNAMICS IN ANALYSIS OF ROAD TRAFFIC ACCIDENTS: MODELING OF THE APPROACHING PHASE}

\section{Robert Janković, Fakultet tehničkih nauka, Novi Sad}

\section{Oblast - MEHANIKA}

Kratak sadržaj - U ovom radu je analizirana prilazna faza vozila za potrebe rekonstrukcije saobraćajnih nezgoda, pomoću Lineikinovog modela. Izvedene su diferencijalne jednačine kretanja vučnog vozila sa poluprikolicom, pomoću Lagranževih jednačina druge vrste za neholonomne sisteme. Primenom programskog paketa Mathematica izvršena je simulacija prilazne faze vozila za bočni sudar.

Ključne reči: dinamika vozila, Lineikinov model, sudar, analiza saobraćajnih nezgoda.

Abstract - In this paper we analysed the approach phase of vehicles for the needs of traffic accident reconstruction using the Lineikin model. Differential equations of motion of a trailer truck with a semi-trailer are formed using Lagrange equations of the second kind for nonholonomic systems. Simulations of the approach phase of vehicles for a side collision were performed using the Mathematica software.

Keywords: vehicle dynamics, Lineikin model, collision, road traffic accident reconstruction.

\section{UVOD}

Ovaj rad je nastao sa idejom da u budućnosti bude od koristi prilikom veštačenja sudara dva vozila u saobraćaju. Za analizu dinamike vozila koriste se različiti matematički modeli. Korišćenje veoma složenih modela koji opisuju kretanje vozila verodostojnije od jednostavnijih modela, može dovesti do određenih matematičkih poteškoća prilikom rešavanja, kao i do mnogo dužeg vremena potrebnog za rešavanje, pa razlozi njihove upotrebe moraju biti opravdani. Da bi se došlo do željenih rezultata, u praksi se često mogu koristiti jednostavniji modeli za proučavanje kretanja vozila u zasebnim ravnima, sa manjim brojem stepeni slobode. Prema tome dinamika vozila se može podeliti na:

- Longitudinalnu (uzdužnu) dinamiku: proučava otpore kretanja, performanse i kočenje;

- Vertikalnu dinamiku: analizira oscilacije vozila usled vertikalnih opterećenja i njihov uticaj na udobnost;

- Lateralnu (poprečnu) dinamiku: analizira bočne sile, kretanje u krivini i uticaj na bezbednost putnika, videti [1].

\section{NAPOMENA:}

Ovaj rad proistekao je iz master rada čiji mentor je bio dr Miodrag Žigić, vanr. prof.
U radu je proučen i prikazan slučaj bočnog sudara vučnog vozila sa poluprikolicom i automobila, pomoću Lineikinovog modela za kretanje vozila.

\subsection{Postavka problema}

Za proučavanje kretanja vučnog vozila sa poluprikolicom pomoću Lineikinovog modela, moraju se usvojiti određene predpostavke pre nego što se krene sa analizom:

- vozilo se kreće po horizontalnoj ravni

- uticaj obrtanja točkova se zanemaruje

- ne dolazi do proklizavanja točkova

- brzine tačaka $A, B$ i $E$ imaju pravce odgovarajućih točkova.

\section{DINAMIKA VUČNOG VOZILA SA POLUPRIKOLICOM}

Pri analizi ovog modela ne koristi se pokretni koordinatni sistem pa će ose nepokretnog koordinatnog sistema biti označene malim slovima $x$ i $y$ kao što je prikazano na slici 1.

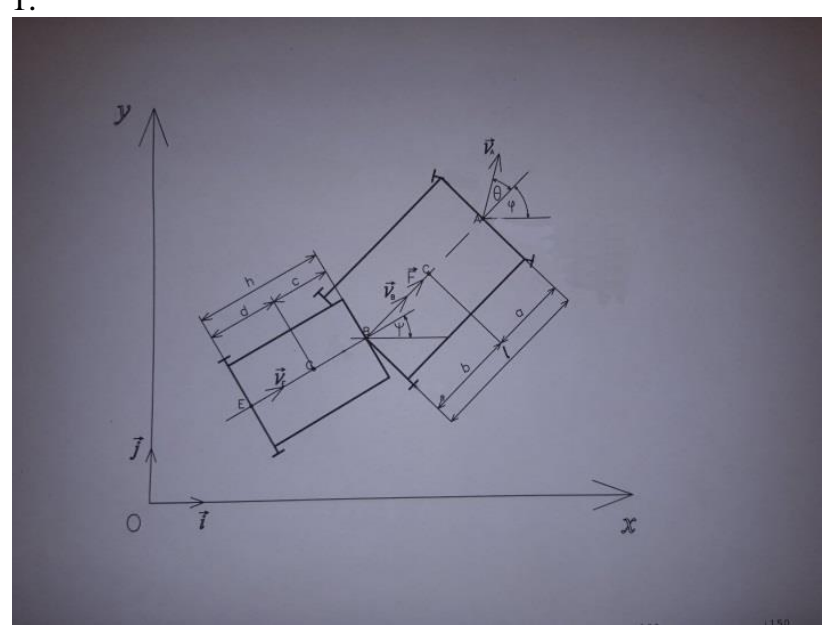

Slika 1. Model vučnog vozila sa poluprikolicom.

Na slici 1 prikazan je model vučnog vozila sa poluprikolicom, koji je izveden na osnovu Lineikinovog modela automobila. Model ima sledeće karakteristike:

- $l$ međuosovinsko rastojanje,

- $a$ rastojanje prednje osovine od centra mase $C$,

- $b$ rastojanje zadnje (pogonske) osovine od centra mase $C$,

- $h$ dužina poluprikolice,

- $c$ rastojanje od prednje stranice poluprikolice do centra mase $G$, 
- $d$ rastojanje od osovine poluprikolice do centra mase $G$,

- $\vec{v}_{E}$ brzina tačke $E$, koja se nalazi na sredini poluprikolice,

- $\vec{v}_{A}$ brzina tačke $A$ koja se nalazi na sredini prednje osovine,

- $\vec{v}_{B}$ brzina tačke $B$ koja se nalazi na sredini zadnje osovine,

- $\vec{F}$ pogonska sila vučnog vozila,

- $\varphi$ ugao koji uzdužna osa vučnog vozila zaklapa sa $x$ osom,

- $\theta$ ugao zakretanja prednjih točkova u odnosu na uzdužnu osu vozila,

- $\psi$ ugao koji uzdužna osa poluprikolice zaklapa sa $x$ osom.

Brzine tačaka $A, B, G$ i $E$ se mogu izraziti na sledeći način:

$$
\begin{aligned}
& \vec{v}_{A}=\dot{x}_{A} \vec{i}+\dot{y}_{A} \vec{j} \\
& \vec{v}_{B}=\dot{x}_{B} \vec{i}+\dot{y}_{B} \vec{j} \\
& \vec{v}_{G}=\dot{x}_{G} \vec{i}+\dot{y}_{G} \vec{j} \\
& \vec{v}_{E}=\dot{x}_{E} \vec{i}+\dot{y}_{E} \vec{j}
\end{aligned}
$$

Koordinate tačaka $A, B, G$ i $E$ su date na sledeći način:

$$
\begin{aligned}
& x_{B}=x_{C}-b \cos \varphi ; y_{B}=y_{C}-b \sin \varphi, \\
& x_{A}=x_{C}-a \cos \varphi ; y_{A}=y_{C}+a \sin \varphi, \\
& x_{G}=x_{C}-b \cos \varphi-c \cos \psi ; y_{G}=y_{C}-b \sin \varphi-c \sin \psi, \\
& x_{E}=x_{C}-b \cos \varphi-h \cos \psi ; y_{E}=y_{C}-b \sin \varphi-h \sin \psi,
\end{aligned}
$$

Za opisivanje ovog sistema koriste se Lagranževe jednačine druge vrste za neholonomne sisteme čiji je osnovni oblik:

$$
\frac{d}{d t} \frac{\partial L}{\partial \dot{q}_{j}}-\frac{\partial L}{\partial q_{j}}=Q_{j}^{*}+\sum_{\beta=1}^{l} \lambda_{\beta} b_{\beta j}(i=1, \ldots, m),
$$

gde su

$$
q_{j}(j=1, \ldots, m)
$$

generalisane kooordinate, a broj generalisanih koordinata je $m=5$, dok su $\lambda_{\beta}(\beta=1, \ldots, l)$ Lagranževi množitelji, videti [2]. Generalisane koordinate određuju položaj sistema u svakom trenutku. Za generalisane koordinate ovog sistema uzete su koordinate centra mase $x_{c}$ i $y_{c}$, ugao zakretanja vozila $\varphi$, ugao zakretanja prednjih točkova $\theta$ i ugao $\psi$ koji uzdužna osa poluprikolice zaklapa sa $x$ osom. Jednačine neholonomnih veza u opštem obliku su predstavljene sledećim izrazom:

$$
\sum_{i=1}^{n} b_{\beta j} \dot{q}_{j}+b_{\beta}=0 \quad(\beta=1,2, \ldots, l),
$$

a njihov broj iznosi $l=3$. To su ograničenja na brzine tačaka $A, B$ i $E$, koje predstavljaju sredinu prednje osovine vučnog vozila, sredinu njegove zadnje osovine i sredinu osovine poluprikolice, respektivno.

Brzine ovih tačaka imaju pravace odgovarajućih točkova, kao što je prikazano na slici 1 . Jednačine neholonomnih veza za razmatrani problem su:

$$
\operatorname{tg} \varphi=\frac{\dot{y}_{B}}{\dot{x}_{B}}, \operatorname{tg}(\varphi+\theta)=\frac{\dot{y}_{A}}{\dot{x}_{A}}, \operatorname{tg} \psi=\frac{\dot{y}_{E}}{\dot{x}_{E}},
$$

iz kojih se, raspisivanjem u oblik (5) određuju koeficijenti $b_{\beta j}$. Broj stepeni slobode:

$$
n=m-l=5-3=2
$$

Lagranžijan $L$ je:

$$
\begin{gathered}
L=E_{k_{1}}+E_{k_{2}}-\Pi=\frac{1}{2} M v_{c}^{2}+\frac{1}{2} J_{C} \dot{\varphi}^{2}+\frac{1}{2} J_{A} \dot{\theta}^{2}+\frac{1}{2} M_{2} v_{G}^{2}+\frac{1}{2} J_{G} \dot{\psi}^{2} \\
\prod=0,
\end{gathered}
$$

gde je:

- $\quad M$ masa vučnog vozila

- $\quad M_{2}$ masa poluprikolice

- $\quad J_{G}$ aksijalni moment inercije poluprikolice za vertikalnu osu koja prolazi kroz tačku $G$,

- $J_{C}$ aksijalni moment inercije vučnog vozila za vertikalnu osu koja prolazi kroz tačku $C$,

- $\quad J_{A}$ aksijalni moment inercije pri zakretanju upravljačkih točkova.

Generalisane sile nepotencijalnih dejstava su prikazane kao $\mathrm{Q}_{\mathrm{j}}^{*}, j \in\left\{x_{c}, y_{c}, \varphi, \theta, \psi\right\}$, a izvedene su iz izraza za virtualni rad nepotencijalnih sila.

$$
\begin{gathered}
Q_{x c}=F \cos \varphi ; Q_{y c}=F \sin \varphi ; \\
Q_{\theta}=M_{A} ; Q_{\varphi}=0 ; Q_{\psi}=0,
\end{gathered}
$$

Iz jednačine (3) kada se uvrste izrazi (8) i (9), uzimajući u obzir koeficijente $b_{\beta j}$ određene iz jednačina neholonomnih veza (6) dobija se sistem diferencijalnih jednačina kretanja neholonomnog sistema:

$$
\begin{aligned}
& M \ddot{x}_{c}=F \cos \varphi+\lambda_{1} \sin \varphi+\lambda_{2} \sin (\varphi+\theta)+\lambda_{3} \sin \psi \\
& M \ddot{y}_{c}=F \sin \varphi-\lambda_{1} \cos \varphi-\lambda_{2} \cos (\varphi+\theta)-\lambda_{3} \cos \psi \\
& J_{C} \ddot{\varphi}=\lambda_{1} b-\lambda_{2} a \cos \theta-\lambda_{3} b \cos (\varphi-\psi) \\
& J_{A} \ddot{\theta}=M_{A} \\
& J_{E} \ddot{\psi}=\lambda_{3} h
\end{aligned}
$$

pri čemu su jednačine neholonomnih veza:

$$
\begin{gathered}
\dot{x}_{c} \sin \varphi-\dot{y}_{c} \cos \varphi+b \dot{\varphi}=0 \\
\dot{x}_{c} \sin (\varphi+\theta)-\dot{y}_{c} \cos (\varphi+\theta)-a \cos \theta \dot{\varphi}=0 \\
\dot{x}_{c} \sin \psi-\dot{y}_{c} \cos \psi+b \cos (\varphi-\psi) \dot{\varphi}+h \dot{\psi}=0
\end{gathered}
$$

Eliminacijom Lagranževih množitelja iz jednačina (10), koristeći sistem (11) dobijaju se diferencijalne jednačine kretanja vučnog vozila sa poluprikolicom, koje će biti rešene numerički. U nastavku sledi rešavanje takvog sistema diferencijalnih jednačina za izabrane vrednosti parametara vučnog vozila sa poluprikolicom i početne uslove.

Pored tog vozila razmotriće se i kretanje automobila čije je kretanje modelirano Lineikinovim modelom, videti [3]. Generalisane koordinate automobila su označene kao generalisane koordinate vučnog vozila, samo što imaju dodat indeks 2.

\section{REŠENJE PROBLEMA I GRAFIČKI PRIKAZ}

Razmotriće se slučaj u kojem dolazi do sudara vučnog vozila sa poluprikolicom i automobila, gde će se anali- 
zirati samo prilazna faza. Izabrani parametri za vučno vozilo sa poluprikolicom su:

$M=4000 \mathrm{~kg} ; l=5.81 \mathrm{~m} ; a=2.3 \mathrm{~m} ; b=2.51 \mathrm{~m} ; M_{p}=5000 \mathrm{~kg}$, $c=2.1 \mathrm{~m}, d=3.2 \mathrm{~m}$,

$J_{C}=8000 \mathrm{kgm}^{2} ; J_{G}=9500 \mathrm{kgm}^{2} ; J_{A}=5.2 \mathrm{kgm}^{2}$,

dok su izabrani parametri za automobil koji se kreće u susret vučnom vozilu:

$$
\begin{gathered}
M_{2}=1750 \mathrm{~kg} ; l_{2}=2.75 \mathrm{~m} ; a_{2}=1.25 \mathrm{~m} ; b_{2}=1.5 \mathrm{~m} ; \\
J_{c 2}=2750 \mathrm{kgm}^{2} ; J_{A 2}=1.2 \mathrm{kgm}^{2}
\end{gathered}
$$

Analiziran je slučaj bočnog sudara. Vučnim vozilom sa poluprikolicom se upravlja pomoću pogonske sile $F$ i obrtnog momenta $M_{A}$, koji utiče na ugao zakretanja pogonskih točkova $\theta$, dok na automobil deluje pogonska sila $F_{2}$ i moment $M_{A 2}$.

\subsection{Slučaj bočnog sudara}

Vučno vozilo sa poluprikolicom skreće ulevo na raskrsnici pod uglom od $90^{\circ}$, kada automobil iz suprotnog smera, koje se kreće translatorno pravolinijski, udara u njega bez prethodnog kočenja.

Pogonska sila $F$ vučnog vozila sa poluprikolicom je konstantna i iznosi $F=7500 \mathrm{~N}$, moment $M_{A}$ je zadat u funkciji vremena tako da se izvrši željeno kretanje, slika 2. Pogonska sila vozila koje se kreće iz suprotnog smera $F_{2}$ je takođe konstantna i iznosi $F_{2}=500 \mathrm{~N}$, dok je moment $M_{A 2}$ jednak nuli kako bi se vozilo kretalo duž saobraćajne trake.

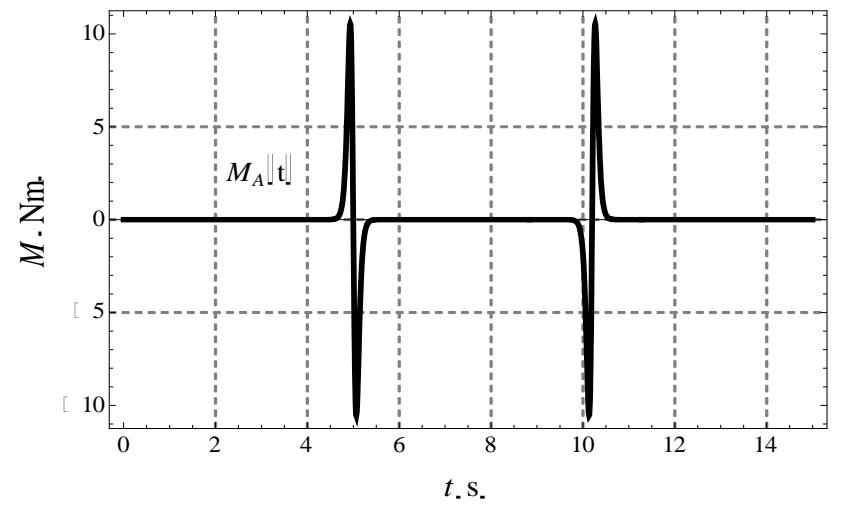

Slika 2. Moment upravljanja tokom skretanja vučnog vozila sa poluprikolicom pod uglom od $90^{\circ}$.

Na slici 3 se vidi da dolazi do zakretanja upravljačkih točkova $\mathrm{u}$ skladu sa zadatom funkcijom momenta upravljanja. Uglovi $\varphi$ i $\psi$ za to vreme rastu od $0^{\circ}$ do $\pi / 2$.

Na slici 4 prikazane su koordinate centra mase vučnog vozila tokom vremena, dok je trajektorija centra mase data na slici 5.

Automobil koji ide u susret vučnom vozilu sa poluprikolicom, kreće se translatorno pravolinijski u skladu sa zadatom pogonskom silom i momentom upravljanja pogonskih točkova, kao i homogenim početnim uslovima.

Generalisana koordinata $x_{C 2}$ centra mase automobila je jedina generalisana koordinata automobila koja se u posmatranom slučaju menja tokom prilazne faze vozila $i$ ovde se neće prikazivati.
Na slici 6 prikazan je položaj vozila u trenutku sudara automobila u vučno vozilo sa poluprikolicom. Oba vozila su vršila zadate manevre do trenutka sudara. Slika je deo simulacije dobijene uz pomoć programskog paketa Mathematica.

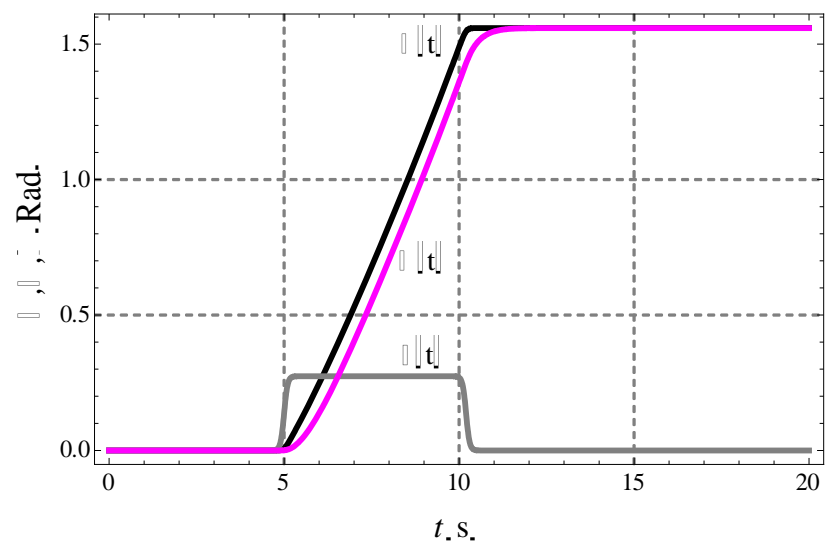

Slika 3. Uglovi $\varphi, \theta$ i $\psi$ vučnog vozila sa poluprikolicom.

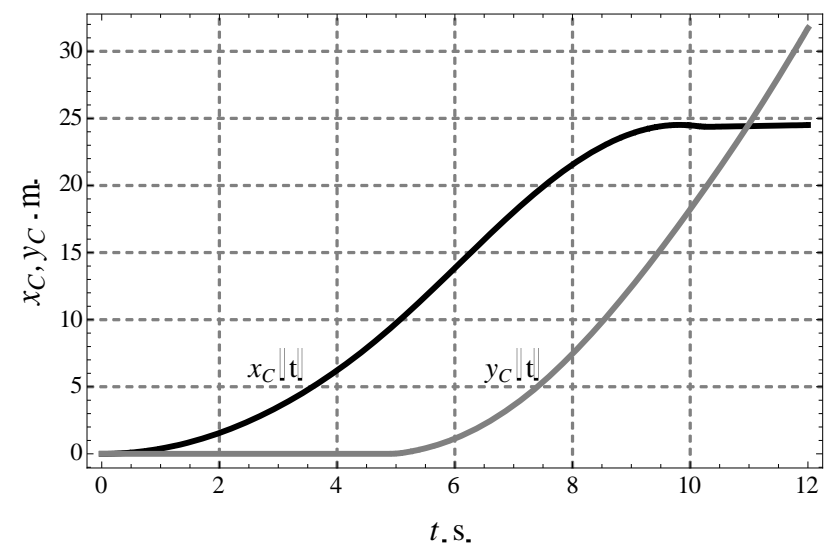

Slika 4. Koordinate centra mase vučnog vozila sa poluprikolicom tokom zadatog manevra.

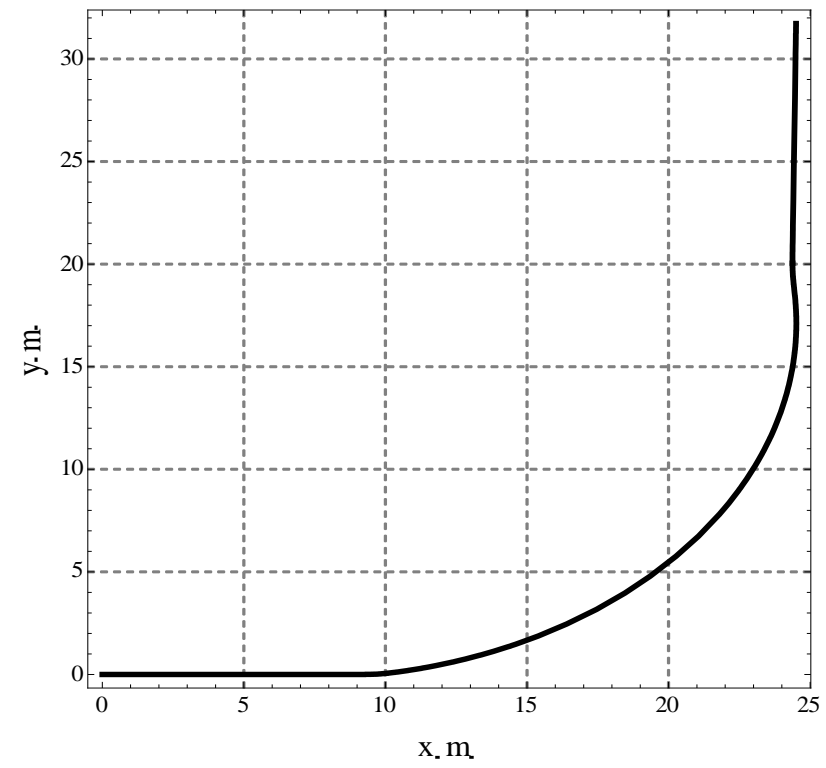

Slika 5. Trajektorija centra mase vučnog vozila tokom zadatog manevra: skretanje u raskrsnici pod uglom od $90^{\circ}$. 


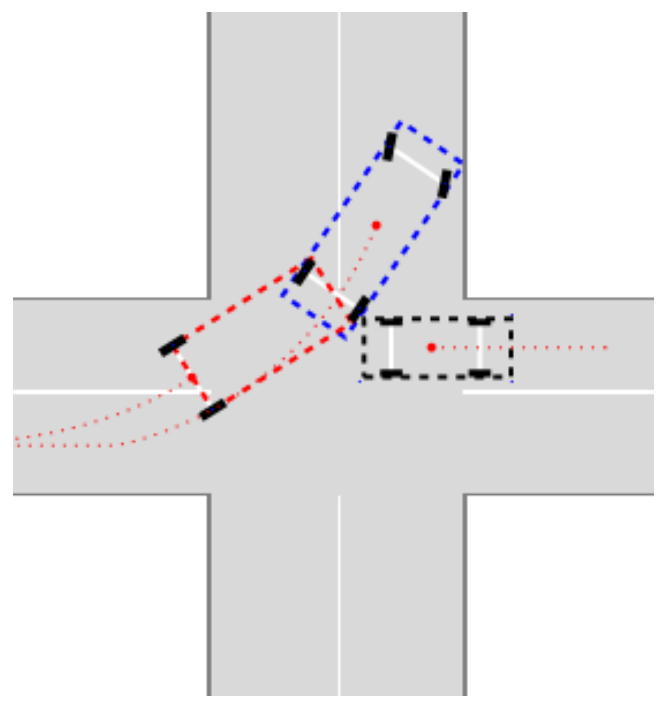

Slika 6. Položaj vučnog vozila sa poluprikolicom $i$ automobila u raskrsnici u trenutku sudara.

\section{ZAKLJUČAK}

U ovom radu su izvedene i rešene diferencijalne jednačine kretanja vučnog vozila sa poluprikolicom i rešenja su prikazana grafički. Rešene su i diferencijalne jednačine kretanja automobila za zadate početne uslove.

Za rešavanje su korišćene Lagranževe jednačine druge vrste za neholonomne sisteme. Analiziran je slučaj u kojem automobil naleće na vučno vozilo sa poluprikolicom koje skreće na raskrsnici ulevo ne poštujući pravo prvenstva prolaza automobila.

Proučena je prilazna faza kretanja vozila do trenutka njihovog kontakta, dok sama faza sudara i faza kretanja vozila nakon sudara do njihovog zaustavljanja ovde nije proučena jer prevazilazi okvire ovog rada i predstavlja temu za dalje istraživanje. Lineikinov model, iako dosta jednostavan, daje pouzdane rezultate i vrlo je upotrebljiv za modeliranje kretanja vozila za određenu klasu problema u analizi saobraćajnih nezgoda.

\section{LITERATURA}

[1] W. Chen, H. Xiao, "Integrated vehicle dynamics and control", Hefei, Wiley, 2016.

[2] D.T.Spasić, "Mehanika: osnove, opšte, proširenja”, Univerzitet u Novom Sadu, u pripremi.

[3] В.В.Добронравов, “Основы механики неголономных систем”, Издательствовысшая школа, Москва, 1970.

\section{Kratka biografija:}

Robert Janković rođen u Doboju 1987. god. Bečelor rad na Fakultetu tehničkih nauka odbranio 2011. god. Iz oblasti Mašinstva - Tehnička mehanika i dizajn u tehnici 